\title{
Lise Öğrencilerinin Demokratik Okul Kültürü Algısı ile Akademik İsteklilikleri Arasındaki İlişkide Okul Bağlılığının Aracılık Rolü
}

\section{Seval KOÇAK*, Mustafa Hami AY**}

Öz: Bu araştırmada lise öğrencilerinin akademik isteklilikleri üzerinde rol oynayan değişkenler üzerinde durulmuştur. Bu amaçla araştırmada öğrencilerin demokratik okul kültürü algısı, okul bağlılıkları ve akademik isteklilikleri arasındaki ilişkiler tespit edilmiştir. İlgili amaç çerçevesinde demokratik okul kültürü algısı ile akademik isteklilik arasındaki ilişkide okul bağlılığının aracılık etkisinin olup olmadığı incelenmiştir. Çalışmanın örneklemini Uşak ili merkez ilçede öğrenimine devam eden 682 lise öğrencisi oluşturmuştur. Veriler Demokratik Okul Kültürü Ölçeği, Okul Bağlılığı Ölçeği ve Akademik İsteklilik ölçeği ile gönüllülük esasıyla toplanmıştır. Araştırma ilişkisel tarama modelinde desenlenmiş; alanyazına dayalı olarak kurulan hipotezler test edilmiştir. Bu kapsamda öncelikle değişkenlere ait ortalamalar, aralarındaki ilişkiler ve değişkenler arası regresyon katsayıları tespit edilmiştir. Sonrasında ise ölçüm modeli hesaplanmış ve aracılık etkisi test edilmiştir. Sobel testi yapılarak aracılık etkisinin tekrar kontrol edilmesi sağlanmıştır. Araştırma bulgularına göre lise öğrencilerinin demokratik okul kültürü algısı ile akademik isteklilikleri arasındaki ilişkide, okul bağlılıklarının aracılık etkisi olduğu saptanmıştır. Elde edilen sonuçlar ışığında uygulayıcılara demokratik okul kültürü oluşturma odaklı öneriler geliştirilmiştir. Araştırmacılara ise gelecek araştırmalara yönelik öneriler sunulmuştur.

Anahtar Sözcükler: Demokratik okul kültürü, Okul bağlılığı, Akademik isteklilik, Lise öğrencileri.

The Mediating Role of School Engagement on the Relationship between High School Students' Perception of Democratic School Culture and Their Academic Aspiration

\footnotetext{
*Dr. Öğrt Üyesi. Uşak Üniversitesi, Eğitim Fakültesi, Eğitim Bilimleri Bölümü, Eğitim Yönetimi Anabilim Dalı, E-mail: sevalkocak85@gmail.com Orcid No: 0000-0002-9064-2335

**Uşak İl Milli Eğitim Müdürlüğü (Uşak Üniversitesi Eğitim Bilimleri Bölümü, Eğitim Yönetimi Anabilim Dalı yüksek lisans mezunu) E-mail: mustafa hami@msn.com ORCID:0000-0001-7964-093X

$\mathrm{Bu}$ araştırma için Uşak Üniversitesi Sosyal ve Beşeri Bilimler Bilimsel Araştırma ve Yayın Etiği Kurulu’ndan (13.04.2020 tarih ve 2020-43 sayılı karar) etik izin alınmıştır.
} 
Abstract: In this study, variables that play a role on the academic aspiration of high school students were emphasized. For this purpose, the relationships between students' perception of democratic school culture, school engagement and academic aspirations were determined. Within the framework of the relevant purpose, it was examined whether school engagement has a mediating effect in the relationship between the perception of democratic school culture and academic aspiration. The sample of the study consisted of 682 high school students studying in the central district of Usak. The data were collected from the students on a voluntary basis with Democratic School Culture Scale, School Engagement Scale, and Academic Aspiration Scale. The research was designed as a relational screening model and hypotheses based on literature were tested. In this context, firstly, the means of the variables, the relationships and the regression coefficients between the variables were determined. Then, the measurement model was calculated and the mediation effect was tested. By doing the Sobel test, the mediation effect was checked again. According to the findings of the research, it was determined that school engagement has a mediating effect in the relationship between high school students' perception of democratic school culture and their academic aspirations. In the light of the results, suggestions have been developed for practitioners relating creating a democratic school culture. Researchers were also offered suggestions for future research.

Key Words: Democratic school culture, School engagement, Academic aspiration, High school students.

\section{Giriş}

Ortaöğretim, öğrencilerin üniversiteye hazırlandıkları, gelecekteki mesleklerine yönelik kararlarının netleşmeye başladığı kritik bir eğitim düzeyini temsil etmektedir. Doğal olarak bu eğitim düzeyindeki öğrencilerin akademik isteklilikleri ve akademik başarıları onların üniversiteyi kazanabilmeleri veya yaşam boyu devam edecekleri mesleklere yönelmeleri açısından büyük önem taşımaktadır (Koçyiğit, Eğmir ve Akçil, 2018). Bununla birlikte sadece Türkiye'de değil dünya genelinde lise ve dengi okullardaki akademik başarı, üniversiteye giriş açısından önemli bir faktör olarak görülmektedir (Gölpek ve Uğurlugelen, 2013; Helms, 2008). $\mathrm{Bu}$ önem ise üniversite eğitiminin iyi bir yaşam kalitesi ve ekonomik kazanç gibi çıktılarla ilişkili olmasından kaynaklanmaktadır (Avery ve Turner, 2012; Chan, 2016). Bu nedenle ortaöğretim öğrencilerinin üniversite giriş sınavında başarı sağlamaya yetecek bir akademik istekliliğe sahip olması oldukça önemli görülmektedir. Nitekim alanyazında akademik 
istekliliğin, akademik başarının öncüllerinden biri olduğuna yönelik ampirik çalışmalar bulunmaktadır (Khattab, 2015; Rothon, Arephin, Klineberg, Cattell ve Stansfeld, 2011). Bu nedenle akademik başarı için akademik istekliliğin güçlendirilmesinin önemli olduğu sonucunu çıkarmak mümkündür.

Ortaöğretim düzeyinin bahsedilen bu önemine rağmen, yapılan ulusal ve uluslararası sınavlar, Türkiye'de lise düzeyinde akademik başarının düşük olduğunu göstermektedir. The Organısatıon for Economic Co-Operatıon and Development (OECD) raporunda da yer aldığı üzere 72 ülkede gerçekleştirilen 2015 PISA sonuçlarına göre Türkiye fen okuryazarlığında 54üncü, matematik okuryazarlığı ve okuma becerilerinde 50nci sırada yer almıştır (OECD, 2015). 2018 PISA sonuçlarına göre lise öğrencileri gelişim göstermiş olsa da, tüm alanlarda OECD ortalamasının oldukça altında kalmıştır (OECD, 2019). Uluslararası sınav sonuçlarının yanında ulusal düzeyde yapılan üniversite giriş sınavları da başka bir tehlikeye işaret etmektedir. Örneğin Ölçme, Seçme ve Yerleştirme Merkezi (ÖSYM) verileri, üniversite giriş sınavına giren 2 milyon 390 bin öğrenciden yaklaşık 629 bin adayın, temel yeterlik test (TYT) sınav barajının altında kaldığını göstermiştir (ÖSYM, 2019). Bu durum Türkiye' de ortaöğretim öğrencilerinin akademik isteklilik ve güdülenmelerindeki düşüklüğe yönelik tehlikeye dikkat çekmektedir. Akademik istekliğin düşük olmasının altında yatan olası nedenlerden biri olarak ise okul bağl1lığındaki düşüklüğü göstermek mümkün görünmektedir.

Lise öğrencileri üzerinde okul bağlılığı değişkenin çalışıldığı Türkiye adresli araştırmalarda, okul bağlılığının orta düzeyde olduğu görülmekte; bu nedenle okul bağlılıklarının arttırılması için gerekli önlemlerin alınması gerektiği üzerinde durulmaktadır (Arastaman, 2009; Argon ve İsmetoğlu, 2016; Kalaycı ve Özdemir, 2013; Yanık, 2018). Yüksel ve Hayırsever (2019) tarafindan yapılan bir çalışmada ise liselerde kendini okula ait hissetmeyen ve okula karşı olumsuz duygular geliştiren öğrenciler olduğu saptanmıştır. Önen (2014) ise lise öğrencilerinin okul bağlılığının bir önceki kademedeki öğrencilere göre düşük olduğunu bulmuştur. Bu sonuca paralel olarak Türkiye'de yapılan diğer çalışmalar, liselerde devamsızlık, geç gelme ve okul terki gibi sorunların yaşandığını göstermektedir (Altınkurt, 2008; MEB-UNICEF, 2013; Elitok-Kesici ve Yengin-Sarpkaya, 2013; Gül, Kıran ve Nasirsi, 2016). Okullarda yaşanan bu sorunlar ise okul bağl1lı̆̆ındaki düşüklüğün davranışsal göstergeleri olarak değerlendirilmektedir (Demir ve Akman-Karabeyoğlu, 2016; Jimerson, Campos ve Greif, 2003; Kızıldağ, Demirtaş-Zorbaz ve Zorbaz, 2017). Bu nedenle lise öğrencilerine, onları okula içsel olarak bağlayacak bir okul ortamı sağlanması gerekmektedir. 
$\mathrm{Bu}$ çalışmanın çıkış noktası, öğrencilerinin demokratik bir okul kültürü ile okula olan bağl1lıklarının gelişebileceği, okul bağlılıklarının gelişmesiyle de akademik istekliliklerinin arttırılabileceği düşüncesi olmuştur. Dolayısıyla bu araştırmanın amacı, lise öğrencilerinin demokratik okul kültürüne yönelik algılarını, okul bağlılıklarını ve akademik istekliliklerini belirlemek; bu değişkenler arasındaki ilişkileri tespit etmektir. Bu amaçla demokratik okul kültürü ile akademik isteklilik arasındaki ilişkide okul bağlılığının aracılık etkisinin olup olmadığı incelenmiştir. Değişkenler arasındaki olası ilişkiler alanyazına dayalı olarak hizpotezlendirilmiş ve kurulan bu hipotezler test edilmiştir.

\section{Kavramsal Çerçeve}

\section{Demokratik Okul Kültürü}

Öğrenciler açısından demokratik okul kültürü, bütün öğrencilerin eşit haklara sahip olduğu, eşit muamele gördüğü, okul olanaklarından adil fayda sağlayabildiği, belirli konularda aktif katılıma ve söz hakkına sahip olduğu bir kültürü yansıtmaktadır (Atalay-Kabasakal ve diğ., 2015). Okulda böyle bir demokratik bir kültürün oluşması tesadüfi değildir. Aksine yönetici ve öğretmenlerin demokratik değerleri hayata geçirme ve demokratik yaşam için gerekli koşulları oluşturma çabalarının bir ürünüdür. (Beane ve Apple, 2007; Işıkgöz, 2016; Morrison, 2008).

Demokratik bir okul ortamı için öğrencilere sağlanması beklenen koşulların başında, kendilerini fiziksel/duygusal olarak güvende hissedecekleri, açık iletişimin sağlandığ hoşgörünün olduğu bir okul kültürü gelmektedir (Şişman, Güleş ve Dönmez, 2010). Bununla beraber konuşma ve ifade özgürlüğü, faaliyet ve etkinliklerde sosyal değerlere vurgu, çeşitliliğe ve azınlık haklarına saygı, bireysel ve kolektif çabaya inanç, ortak fayda ve öğrenme yaşantılarında öğrenciyi merkeze alma gibi özellikler de demokratik bir okul kültürünün göstergeleri arasında gösterilmektedir (Beane ve Apple, 2007; Hecht ve Ram, 2008). Dolayısıyla demokratik bir okul bağlamı içinde demokratik değer, tutum ve inançların davranışa dönüştüğü, her türlü fikre saygılı ancak eleştirel yaklaş1lan, öğrencilere sadece kuralların uygulatıldığı değil yetkilerin paylaşıldığı bir yapılanma söz konusudur (Bickmore, 2001).

Öğretmenlerin demokratik kültür gereklerini sınıfa taşıyabilmeleri de, bu konuda etkili bir lider desteği ile mümkün görünmektedir (Thornberg ve Elvstrand, 2012). Bu nedenle öncelikle okul yöneticilerinin paylaşım, işbirliği, kararlara katılım ve çeşitliliğe saygı gibi öğelerin olduğu demokratik bir okul kültürü oluşturması sonrasında da öğretmenleri bu konuda 
motive etmesi büyük önem taşımaktadır (Gözübüyük, 2011; Gül ve Saraç, 2018; Kaya, 1996). $\mathrm{Bu}$ nedenle alanyazında demokratik okul kültürü yaratmada yönetici yeterliklerinin ve yönetimde demokratik değerleri hayata geçirebilme becerisinin gerekliliğine dikkat çekilmekte; eğitim olanaklarına eşit erişimi, sosyal adaleti, özerkliği ve hesapverebilirliği sağlamanın böylesi bir kültür oluşturmadaki önemi vurgulanmaktadır (Bäckman ve Trafford, 2007; Louis, 2003; Møller, 2006; Şişman, Güleş ve Dönmez, 2010).

Demokratik bir okul ortamında öğrenim görmek, öğrencilerin gelişimi ve eğitimin amaçlarına ulaşması açsından oldukça önemlidir. Nitekim Dewey (1916), ancak demokrasinin yaşatıldığ1 okullarda özgür düşüncenin gelişebileceğini, bireylerin kişisel güçlerini keşfedebileceklerini, öğrenme yaşantısına aktif katılım ve işbirliği sağlayabileceklerini ifade etmektedir. Bununla beraber öğrencilerin korkmadan öğrenme sürecine aktif katılımının ve etkin öğrenme yaşantılarının ancak demokratik okullarda olabileceği belirtilmektedir (Duman ve Koç, 2004; Thornberg ve Elvstrand, 2012).

\section{Okul Bağlılığı: Bilişsel, Duyuşsal ve Davranışsal Boyutları}

Öğrencilerin okullarında akademik ve sosyal yönden başarılı olmaları, kendilerini okullarında nasıl hissettikleri ve okullarını ne kadar benimsedikleri ile ilişkili görünmektedir. Okul bağl1lığı olarak ifade edilen bu kavram, Finn ve Voelkl (1993) tarafindan, öğrencilerin okula devam halini istekle sürdürmesi ve kurallara uygun davranışlar sergileyerek okuldaki ve sınıftaki tüm aktivitelere gönüllü katılım göstermesi olarak tanımlanmaktadır. Jimerson ve arkadaşları (2003) ise okul bağlılığını öğrencilerin akademik çaba sarfetmeleri, sınıf içindeki olumlu davranışları, okulda ders dışı etkinliklere katılım göstermeleri, kişiler arası ilişkilerinin sağlamlığı ve kendilerini okulun bir parçası olarak görüp özdeşleşmeleri ile açıklamaktadır. Bu çerçevede okul bağl1lı̆g1 olan öğrenciler, öğrenmeye daha yatkın, okul deneyimlerinden, öğretmen ve akran ilişkilerinden keyif alan, okulla özdeşleşmiş, öğretmenlerin kendileri ile ilişkilerini olumlu algılayan ve okula istekle devam etme eğilimi yüksek olan bireyler olarak görülmektedir (Marks, 2000; Silins ve Mulford, 2004). Bu nedenle okul bağl1lı̆̆1, öğrencilerin akademik ve sosyal başarıları açısından oldukça önemli görülmektedir (Osterman, 2000).

Okul bağlılığı, öğrenci tutumlarından, davranışlarından ve akademik çabadan anlaşılabilen çok boyutlu bir kavramdır. Önen (2014) okul bağlılı̆ğ kavramının okula devam etme ya da akademik çaba gösterme gibi daha kolay gözlemlenebilen davranışlar yanında öğrencilerin psikolojik durumları ile tanımlanan karmaşık bir yapı olduğunu ileri sürmektedir. 
Bu bağlamda okul bağlılığı bilişsel, duyuşsal ve davranışsal boyutlarda incelenmektedir (Fredricks, Blumenfeld, Friedel ve Paris, 2005; Jimerson ve diğ., 2003).

Bilişsel bağl1lık, öğrencilerin okuldaki öğrenme yaşantısının gelecekte kendisine sağlayacağ1 yarara verilen değer, özdenetim, öğrenmeye yönelik amaç/strateji yönelimli olma ile ilişkilendirilmektedir (Appleton, Christenson, Kim ve Reschly, 2006). Bilişsel bağlılığı olan öğrencilerin okuldaki karmaşık ve zor işleri yapmaktan kaçmadıkları, okuldaki etkinlikleri ve öğrendiklerinin altında yatan nedenleri anlamada etkin oldukları belirtilmektedir (Arastaman, 2009). Dolayısıyla öğrenmeye yönelik inanç ve bu uğurda yapılan stratejik yatırımlar bilişsel bağl1lığın bir göstergesi kabul edilmektedir (Özdemir, 2017). Duyuşsal bağl1lık, öğrencilerin okulda bulunmaktan mutluluk duyması, görevlerini yerine getirirken heyecan duyması ve okulu eğlenceli bulması ile ilişkilidir (Lippman ve Rivers, 2008). Bir bakıma okulu hangi duygularla tanımladığının ve okula yönelik nasıl tepkiler geliştirdiğinin bir yansımasıdır (Wang ve Holcombe, 2010). Davranışsal bağlılık ise, okulda eylem ve etkinlik başlatma, etkinliklere katılım gösterme ve odaklanma özellikleriyle açıklanmakta (Skinner, Furrer, Marchand ve Kindermann, 2008); öğrencilerin okul kural ve normlarına uyması, verilen görev ve sorumlulukların yerine getirilmesi, akran ve öğretmenleriyle aktif ilişkiler kurması olarak ifade edilmektedir (Lippman ve Rivers, 2008).

\section{Akademik İsteklilik}

Akademik isteklilik Plucker (1996) tarafından öğrencilerin yükselme isteği, okuldan ilham almada açıklık, yüksek başarı güdüsü, okuldan keyif alma ve okulda öğrendiklerinin ileriki yaşantısında faydalı olacağını bilerek azimli davranma eğilimleriyle açıklanmaktadır. Bu kapsamda akademik isteklilik, (i) öğrencilerin okul içi etkinliklerini içsel bir motivasyonla yapma istek ve arzusu ve (ii) öğrencilerin belirlediği hedefe doğru ilerleme ve yükselme isteği olmak üzere iki önemli temele dayanmaktadır (Plucker, 1998). Başka bir tanımlamada ise akademik isteklilik, içsel bir motivasyona dayalı olarak formal eğitimine büyük ölçüde devam etme arzusu şeklinde uzun dönem çıktılarla ifade edilmektedir (Redd, Brooks ve McGarvey, 2001; Smith, Mann, Georgieva, Curtis, ve Schimmel, 2016).

Akademik istekliliğe sahip olma, hem başarının ve hem de öğrencilerde var olan tüm potansiyelin yakalanmasında önemli bir faktör olarak değerlendirilmektedir. Bu durum eğitimcileri, akademik istekliliğin öncüllerini anlamaya ve öğrencilere destek olmaya yönlendirmektedir (Sanders, Munford ve Boden, 2017; Smith vd., 2016). Bununla beraber akademik isteklilik, zorlu durumlarına rağmen öğrencilerin başarıya yönelik kararlılıklarında 
belirleyici bir etmen olarak önemini korumaktadır (Shankar, Ip ve Khalema, 2017). Bu bakımdan öğrencilerin akademik istekliliklerinin desteklenmesinde, sağlanacak dışsal faktörlerin oldukça önem taşıdığını söylemek mümkündür.

\section{Demokratik Okul Kültürü, Okul Bağlılığı ve Akademik İsteklilik Arasındaki} İlişkiler

Okul müdürlerince oluşturulan demokratik okul kültürünü, öğrencilerin okula bağlılığını ve okula devamlılığını etkileyen önemli etmenler arasında görmek mümkündür. Örneğin Leithwood ve Jantzi (2000) tarafından yapılan bir çalışmada okul müdürü tarafından sergilenen liderlik davranışlarının ve oluşturulan okul koşullarının öğrenci bağlılığı üzerinde doğrudan ve dolaylı etkilerinin olduğu saptanmıştır. Yapılan farklı çalışmalarda da öğrencilerin okulun yönetsel süreçlerine katılmaları, okulda önemsendiklerini ve kabul gördüklerini bilmeleri, öğretmen, yönetici ve akranlarıyla etkili iletişim süreci içinde fikirlerini rahatça ifade edebilmeleri, öğretmenlerden destek görmeleri ile okul bağlılıkları arasında anlamlı ilişkiler olduğu saptanmıştır (Argon ve İsmetoğlu, 2016; Bilgin ve Taş, 2018; Cemalcılar, 2010; Yavrutürk, 2019). Benzer şekilde yönetime öğrenci katılımı, kural sisteminin adil işletilmesi, her öğrencinin eşit düzeyde akademik etkinlilerden faydalanması, seçme şansı gibi okul özellikleri de okul bağlılığını arttıran etmenler arasında görülmektedir (Newmann, 1981). Bu çalışmalar 1şığında Hipotez 1. şu şekilde ifade edilmiştir:

Hipotez 1. Demokratik okul kültürü algısl, okul bağlllı̆̆ının anlamlı bir yordaylcisıdır.

Demokratik bir okulun, sadece öğrencinin okula bağlılığı değil, yanı zamanda başarısı üzerinde de etkili olduğuna ilişkin önemli görüşler bulunmaktadır. Bu görüşler demokratik bir okulda, örgütsel etkililiğin artacağına, öğrenci başarısının olumlu yönde bir eğilim göstereceğine ve okul süreçlerine aktif katılım sağlayan, kendini rahtça ifade edebilen öğrencilerde anlamlı öğrenmelerin sağlanabileceği konusunda birleşmektedir (Duman ve Koç, 2004; Gümüşeli, 2001; Yağcı, 1998). Ayrıca demokratik bir okul yönetiminin öğretmen motivasyonu üzerinden öğrenci başarısına katkı sağladığı ifade edilmektedir (Arslan, 2012). Bu bağlamda Hipotez 2. şu şekilde kurulmuştur:

Hipotez 2. Demokratik okul kültürü algısı, akademik istekliliğin anlamlı bir yordayıcısıdır.

Öğrencilerin akademik istekliliklerinin okul bağlılıkları ile ilişki olduğunu söylemek mümkün görünmektedir. Bu kapsamda Wang, Haertel ve Walberg, (1997) öğrencilerin 
akademik başarılarını arttırmanın yolarından birini öğrenciyi okul yaşantısına bağlayan etkinlikler olduğunu ileri sürmüştür. Ayrıca Veiga, Robu, Moura, Goulão ve Galvão (2014) tarafından yapılan bir çalışmada okul bağlılığı ile akademik isteklilik arasında pozitif bir ilişki olduğu tespit edilmiştir. Bu bağlamda Geckova, Tavel, Van Dijk, Abel ve Reijneveld (2010) okula yönelik olumlu tutumları akademik istekliliğin gelişimi için temel koşul olarak değerlendirmişlerdir. Dahası okul bağlılığının, her zorluğa karşı akademik çaba sarfetme davranışı üzerinde de önemli bir rol oynadığı belirtilmiştir (Finn ve Rock, 1997). Bu çalışmalar 1şığında Hipotez 3.; değişkenler arası tüm ikili ilişkiler düşünüldüğünde Hipotez 4. şu şekilde kurulmuştur:

Hipotez 3. Okul bağlılı̆̆l, akademik istekliliğin anlamlı bir yordayıcısıdır.

Hipotez 4. Demokratik okul kültürü ile akademik isteklilik arasındaki ilişkide okul bağlılı̆̆ının aracılık etkisi vardır.

\section{Yöntem}

Lise öğrencilerinin demokratik okul kültüre ilişkin algıları, okul bağlılıkları ve akademik isteklilikleri arasındaki ilişkilerin belirlendiği bu araştırma, ilişkisel tarama modelinde desenlenmiştir. Bu bağlamda öncelikle öğrencilerin demokratik okul kültürü algısı, okul bağlılıkları ve akademik isteklilikleri tespit edilmiş, bunlar arasındaki hipotezlenmiş yapısal ilişkiler test edilmiştir.

\section{Evren ve Örneklem}

Bu çalışma Uşak il merkez ilçesinde, 2019-2020 öğretim yılında öğrenimine devam eden ortaöğretim öğrencileriyle yürütülmüştür. Uşak İl Milli Eğitim Müdürlüğü verilerine göre 2019-2020 öğretim yılında, Uşak ili merkez ilçedeki devlet liselerinde öğrenim gören 11512 öğrenci, araştırmanın evrenini oluşturmuştur. \%5’lik bir hata payı ile hesaplanan örneklem büyüklüğünün 372 olduğu tespit edilmiştir (Krejcie ve Morgan 1970). Veriler Uşak ili merkez ilçedeki 22 lise arasından random olarak seçilen 14 farklı lisede öğrenim gören öğrencilerle gerçekleştirilmiştir. Ölçeklerin geri dönüş oranlarında yaşanabilecek olası sorunlar göz önüne alınarak 720 ölçek uygulanmıştır. Veriler gönüllülük esasına dayalı olarak araştırmacılar tarafından yüz yüze toplanmıştır. 682 veri analize dâhil edilmiştir. Araştırmaya katılan öğrencilere ait bilgiler Tablo 1'de sunulmuştur.

Tablo 1. Araştırmaya Katılan Öğrencilere Yönelik Bilgiler

$\begin{array}{ll}\text { Cinsiyet } & \text { Kadın: } 414(\% 60.7) \\ & \text { Erkek: } 268(\% 39.3)\end{array}$


Okul Türü Anadolu-Fen Liseleri: 454 (\%66.6)

Mesleki-Teknik ve İmam-Hatip Liseleri: 228 (\%33.4)

\begin{tabular}{ll}
\hline Sınıf Düzeyi & Lise 1. Sınıf: $79(\% 11.6)$ \\
& Lise 2. Sinıf: $280(\% 41.1)$ \\
& Lise 3. Sinıf: $254(\% 37.2)$ \\
& Lise 4. Sinıf: $69(\% 10.1)$ \\
\hline Toplam & 682 \\
\hline
\end{tabular}

Tablo 1’den anlaşıldığı üzere araştırmaya katılanların 414’ü (\%60.7) kadın, 268’i (\%33.4) erkek öğrencilerden oluşmaktadır. Bu öğrencilerin 545’ü (\%66.6) Anadolu veya fen liselerinde, 228’i (\%33.4) ise meslek ve imam-hatip liselerinde öğrenimine devam etmektedir. Bununla birlikte öğrencilerin 79’unun (\%11.6) lise birinci, 280’inin (\%41.1) lise ikinci, 254’ünün (\%37.2) lise üçüncü ve 69’unun ise (\%10.1) lise dördüncü sınıfta öğrenim gördüğü görülmektedir.

\section{Veri Toplama Araçları}

Demokratik okul kültürü ölçeği: Araştırmada öğrencilerin demokratik okul kültürü algılarının belirlenmesinde Atalay-Kabasakal vd. (2015) tarafından geliştirilen "Demokratik Okul Kültürü Ölçeği” kullanılmıştır. 5’li Likert tipindeki ölçek, 26 madde ve tek faktörden oluşmaktadır. Ölçme aracının geliştirilmesi sürecinde yapılan analizler, ölçeğin liselerde öğrenim gören öğrencilerin demokratik okul algılarını ölçmede geçerli ve güvenilir bir araç olduğunu göstermiştir (Atalay-Kabasakal vd., 2015). Ölçeğin bu çalışma için de geçerli ve güvenilir bir araç olup olmadığının test edilmesinde doğrulayıcı faktör analizi (DFA) yapılmış, Cronbach’s Alpha katsayısı hesaplanmıştır. DFA sonucunda elde edilen uyum iyiliği değerleri $\left(\chi^{2}=651.43 ; d f=295 ; \chi^{2} / d f=2.20 ; G F I=0.97 ; A G F I=0.97 ; R M S E A=0.04 ; C F I=0.95 ; N F I=0.92\right)$ olarak hesaplanmıştır. Ayrıca ölçeğe ait Cronbach's alpha katsayısının 0.95 olduğu tespit edilmiştir.

Okul bağlılı̆̆ ölçeği: Öğrencilerin okul bağl1lıklarını ölçmek üzere Fredricks ve arkadaşları (2005) tarafindan geliştirilen Çengel, Totan ve Çöğmen (2017) tarafından Türkçeye uyarlanan Okul Bağlılığı Ölçeği kullanılmıştır. 5’li Likert tipindeki ölçek 19 madde ve üç boyuttan oluşmaktadır. Ölçeğin “davranışsal bağlılık” boyutu 5, “duyuşsal bağglılık” boyutu 6 ve "bilişsel bağglllık" boyutu ise 8 maddeden oluşmaktadır. Uyarlama çalışması kapsamında ölçeğin Türk kültüründe kullanılabilecek geçerli ve güvenilir bir araç olduğu tespit edilmiştir (Çengel ve diğ., 2017). Bu araştırma için de ölçeğin geçerlik ve güvenirlik çalışmaları yapılmıştır. Yapılan DFA sonucunda elde edilen uyum iyiliği değerleri ise şu şekildedir: 
Ölçeğin tamamı ve boyutları için güvenirlik katsayıları ise; davranışsal bağlılık boyutu için: .70; duyuşsal bağlılık boyutu için: 0.76 ; bilişsel bağlılık boyutu için: 0.79 ve ölçeğin tamamı için: 0.87 olarak hesaplanmıştır.

Akademik isteklilik ölçeği: Öğrencilerin akademik istekliliklerinin belirlenmesinde Plucker (1996) tarafından geliştirilen, Arastaman ve Özdemir (2019) tarafindan Türkçeye uyarlanan Akademik İsteklilik Ölçeği kullanılmıştır. Ölçek 5'li Likert tipinde olup 21 madde ve 5 boyuttan oluşmaktadır. "Yükselme isteği”” boyutu 5 maddeden, “Okula yönelik ilham” boyutu 3 maddeden, “başarı güdüsü” boyutu 6 maddeden, “okuldan ve yaşamdan keyif alma” boyutu 4 maddeden ve "okulun taşıdı̆̆ önem” boyutu 3 maddeden oluşmaktadır. Ölçeğin uyarlanması sürecinde yapılan analizler, Akademik İsteklilik Ölçeği’nin Türk kültürü için geçerli ve güvenilir bir araç olduğunu göstermiştir (Arastaman ve Özdemir, 2019). Ölçeğin bu çalışma için de geçerlik ve güvenirlik çalışmaları yapılmıştır. Yapılan DFA sonucunda elde edilen değerler; $\quad\left(\chi^{2}=766.21 ; d f=177 ; \chi^{2} / d f=4.32 ; G F I=0.97 ; A G F I=0.96 ; R M S E A=0.07 ; C F I=0.93\right.$; $N F I=0.92$ ) olarak hesaplanmıştır. Ölçeğin güvenirlik katsayıları ise; yükselme isteği boyutu için: 0.75; okula yönelik ilham boyutu için: 0.76; başarı güdüsü boyutu için: 0.70; okuldan ve yaşamdan keyif alma boyutu için: 0.82; okulun taşıdığı önem boyutu için: 0.86 ve ölçeğin tamamı için: 0.88 olarak belirlenmiştir.

Araştırmada kullanılan ölçeklerin geçerlik ve güvenirlik çalışmaları kapsamında elde edilen değeler, alanyazında yer alan değer aralıklarına dayalı olarak değerlendirilmiştir (Hooper, Coughlan and Mullen, 2008; Kline, 2011). Bu şekilde araştırmada kullanılan tüm ölçeklerin ilgili örneklem için geçerli ve güvenilir araçlar olduğuna karar verilmiştir.

\section{Verilerin Analizi}

Hipotezlerin test edilmesi için gerekli analizler gerçekleştirilmeden önce, verilerin analize hazır hale getirilmesi için ön analizler yapılmıştır. Bunun için öncelikle kayıp veri ve uç değerler tespit edilmiştir. Verilerin normal dağılım gösterip göstermediğinin belirlenmesi için basıklık çarpıklık katsayıları incelenmiş, değerlerin \pm 1 aralığında olduğu görülmüştür. Bununla birlikte dağılım grafikleri değerlendirilmiştir. Çok değişkenli uç değer analizi için Mahalonobis uzaklıkları hesaplanmıştır. Tüm bu ön analizler sonucunda verilerin normal dağılım gösterdiği görülmüş, 682 verinin analize dâhil edilmesine karar verilmiştir. Çoklu bağlantılılık sorunu olup olmadığının belirlenmesinde bağımsız değişkenler arasındaki 
korelasyon katsayıları, Variance Inflation Factor (VIF) ve tolerans değerleri incelenmiş, çoklu bağlantılılık sorunu olmadığı sonucuna ulaşılmıştır.

Demokratik okul kültürü ve akademik isteklilik arasındaki ilişkide okul bağlılığının aracılık etkisi test edilmeden önce betimsel istatistikler yapılmıştır. Bu kapsamda değişkenlere ait aritmetik ortalama ve standart sapmalar hesaplanmış, değişkenler arası korelasyon katsayıları tespit edilmiştir. Bunun yanında değişkenler arasındaki doğrudan yollara ilişkin standartlaştırılmış regresyon katsayıları hesaplanmıştır. Bu analizlerden sonra araştırma hipotezlerinin test edilebilmesi için öncelikle ölçüm modeli sınanmış, değişkenler arası ilişkiler ve modele ilişkin uyum iyiliği indeksleri değerlendirilmiştir. Sonrasında ise okul bağlılığının aracı değişken olarak analize dâhil edildiği yapısal model sınanmış, yol katsayıları ve uyum iyiliği değerleri incelenmiştir. Ölçüm modelindeki değerler ile aracılık etkisinin test edildiği modeldeki yol katsayıları değerlendirilmiştir. Şimşek’e (2007) göre ölçüm modelinde bağımsız ve bağımlı değişken arasındaki ilişki katsayısı, aracı değişkenin test edildiği modelde düşüyor ve istatistiksel olarak anlamsızlaşıyorsa aracılık etkisinden söz etmek mümkündür. $\mathrm{Bu}$ çalışmada da okul bağlılığının aracılık etkisi bu yöntemle test edilmiştir. Aracılık etkisinin tekrar kontrol edilmesi için sobel testi gerçekleştirilmiştir. İlgili hesaplama Dr. Kristopher J. Preacher'ın "Calculation for the Sobel Test ${ }^{\dagger}$ ” sayfasındaki formül kullanılarak yapılmıştır.

\section{Bulgular}

Kurulan hipotezlerin test edilmesinden önce değişkenlere ait betimsel istatistikler hesaplanmıştır. Bu çerçevede demokratik okul kültürüne yönelik öğrenci algıları, öğrencilerin okula bağlılıkları ve akademik istekliliklerine ilişkin aritmetik ortalama ve standart sapmalar hesaplanmıştır. Bununla birlikte değişkenler arası korelasyon katsayıları tespit edilmiştir. Aritmetik ortalama, standart sapma ve korelasyon değerleri Tablo 2’de gösterilmiştir.

Tablo 2'de görüldüğü gibi lise öğrencilerinin demokratik okul kültürü algıları ( $\bar{X}=2.93)$ okul bağlılıkları $(\bar{X}=3.05)$ ve akademik isteklilikleri $(\bar{X}=3.23)$ "orta derecede katılım” düzeyindedir. Okul bağlılıklarına ilişkin ortalamalara bakıldığında en yüksek ortalamanın davranışsal bağlılık ( $\bar{X}=3.62)$, en düşük ortalamanın ise duyuşsal bağl11ı̆ga $(\bar{X}=2.77)$ ait olduğu saptanmıştır. Akademik istekliliğin boyutlarına bakıldığında ise en yüksek ortalamanın yükselme isteği $(\bar{X}=3.75)$, en düşük ortalamanın ise okula yönelik ilham $(\bar{X}=2.62)$ boyutlarına ait olduğu görülmüştür. Değişkenler arası korelasyon katsayıları demokratik okul kültürü ile okul bağlılığı ve akademik isteklilik arasında orta düzeyde, pozitif yönlü, anlamlı bir ilişkiler

\footnotetext{
${ }^{\dagger}$ http://quantpsy.org/sobel/sobel.htm
} 
olduğuna işaret etmiştir $\left[\left(r_{1 \times 2}=0.65 ; p<0.001\right) ;\left(r_{1 \times 6}=0.58 ; p<0.001\right)\right]$. Bununla birlikte okul bağlılığı ile akademik isteklilik arasında yüksek düzeyde, pozitif yönlü, anlamlı bir ilişki olduğu görülmüştür $\left[\left(r_{2 \times 6}=0.73 ; p<0.001\right)\right]$. 
$\begin{array}{lll}\text { doi: 10.33711/yyuefd.800885 Araştırma Makalesi } & \text { ISSN: 1305-2020 }\end{array}$

Tablo 2. Değişkenlere ait Betimsel İstatistikler ve Korelasyon Matrisi

\begin{tabular}{|c|c|c|c|c|c|c|c|c|c|c|c|c|c|}
\hline & Ort & Ss & 1 & 2 & 3 & 4 & 5 & 6 & 7 & 8 & 9 & 10 & 11 \\
\hline 1. Demokratik Okul Kültürü & 2.93 & 0.823 & - & & & & & & & & & & \\
\hline 2. Okul Bağglılı̆̆l (Toplam) & 3.05 & 0.680 & $0.648^{*}$ & - & & & & & & & & & \\
\hline 3. Davranışsal Băğlllık & 3.62 & 0.842 & $0.511^{*}$ & $0.747^{*}$ & - & & & & & & & & \\
\hline 4. Duyuşsal Bağglılık & 2.77 & 0.864 & $0.539^{*}$ & $0.790^{*}$ & $0.374^{*}$ & - & & & & & & & \\
\hline 5. Bilişsel Bağlılık & 2.91 & 0.798 & $0.537^{*}$ & $0.890^{*}$ & $0.549^{*}$ & $0.541^{*}$ & - & & & & & & \\
\hline 6. Akademik İsteklilik (Toplam) & 3.23 & 0.662 & $0.580^{*}$ & $0.729^{*}$ & $0.651^{*}$ & $0.591^{*}$ & $0.567^{*}$ & - & & & & & \\
\hline 7. Yükselme İsteğ $i$ & 3.75 & 0.886 & $0.342^{*}$ & $0.461^{*}$ & $0.589^{*}$ & $0.230^{*}$ & $0.358^{*}$ & $0.754^{*}$ & - & & & & \\
\hline 8. Okula Yönelik İlham & 2.62 & 1.005 & $0.455^{*}$ & $0.590^{*}$ & $0.313^{*}$ & $0.640^{*}$ & $0.467^{*}$ & $0.612^{*}$ & $0.168^{*}$ & - & & & \\
\hline 9. Başarl Güdüsü & 3.40 & 0.749 & $0.437^{*}$ & $0.574^{*}$ & $0.609^{*}$ & $0.367^{*}$ & $0.463^{*}$ & $0.829^{*}$ & $0.685^{*}$ & $0.336^{*}$ & - & & \\
\hline 10. Okuldan ve Yaşamdan Keyif Alma & 2.73 & 1.011 & $0.366^{*}$ & $0.452^{*}$ & $0.314^{*}$ & $0.476^{*}$ & $0.322^{*}$ & $0.646^{*}$ & $0.304^{*}$ & $0.356^{*}$ & $0.361^{*}$ & - & \\
\hline 11. Okula Yönelik Önem & 3,27 & 1,146 & $0.507^{*}$ & $0.558^{*}$ & $0.438^{*}$ & $0.494^{*}$ & $0.440^{*}$ & $0.697^{*}$ & $0.363^{*}$ & $0.526^{*}$ & $0.445^{*}$ & $0.263^{*}$ & - \\
\hline
\end{tabular}

$N=682,{ }^{*} p<0.001$ 
$H 1, H 2$ ve $H 3$ 'ün test edilmesi için değişkenler arası doğrudan etkiler regresyon analizleri ile incelenmiştir. Tablo 3'te doğrudan yollara ilişkin standartlaştırılmış regresyon katsayıları, standart hata değerleri ve açıklanan varyans oranları verilmiştir.

Tablo 3. Doğrudan Etkilere Yönelik Standartlaştırılmış Regresyon Ağırlıkları

\begin{tabular}{llllll}
\hline & & $\beta$ & $t$ & $R^{2}$ \\
\hline Doğrudan Yollar & & & & \\
\hline Demokratik Okul Kültürü & $\longrightarrow$ & Okul Bağlılığ1 & $0.648^{*}$ & 22.196 & 0.420 \\
Okul Bağlılığ1 & $\rightarrow$ & Akademik İsteklilik & $0.729 *$ & 27.785 & 0.532 \\
Demokratik Okul Kültürü & Akademik İsteklilik & $0.580^{*}$ & 18.576 & 0.337 \\
\hline $\mathrm{N}=682{ }^{*} \mathrm{p}<0.05$ & & & &
\end{tabular}

Tablo 3'te görüldüğü üzere doğrudan yapılan üç farklı regresyon analizlerine göre demokratik okul kültürü algısı hem okul bağlılığını $(\beta=.648, p<.05)$ hem de akademik istekliliği $(\beta=.580, p<.05)$ anlamlı ve pozitif yönde yordamaktadır. Ayrıca okul bağlılı̆ğ, akademik istekliliğin anlamlı bir yordayıcısıdır $(\beta=.729, \quad p<.05)$. Demokratik okul kültürü algısı okul bağlılığındaki varyansın \%42'sini, akademik isteklilikteki varyansın ise \%34'ünü açıklamaktadır. Öğrencilerin okul bağlılığı ise akademik istekliliklerinin \%53’ünü anlamlı bir şekilde yordamaktadır. Doğrudan yollara yönelik standartlaştırılmış regresyon katsayıları $H 1$, $H 2$ ve $H 3$ 'ün doğrulandığını göstermiştir.

H4'ün test edilerek aracilık etkisine karar verilebilmesi için öncelikle “ölçüm modeli” hesaplanmıştır. Hesaplanan ölçüm modeline göre demokratik okul kültürü algısı ile akademik isteklilik arasında 0.77 düzeyinde; demokratik okul kültürü algısı ile okul bağlılığı arasında 0.54 düzeyinde ve okul bağlılı̆̆ ile akademik isteklilik arasında 0.85 düzeyinde anlamlı ilişkiler olduğu tespit edilmiştir. Ölçüm modeline ilişskin uyum iyiliği değerlerine bütün olarak bakıldığında, modelin doğrulandığg görülmüştür (Bkz. Tablo 4). Okul bağlılığının iki değişken arasındaki ilişkideki aracılık rolünün tespit edilebilmesi için, “aracılık modeli” sınanmıştır. Modelde okul bağlılığı değişkeni, demokratik okul kültürü algısı ile akademik isteklilik arasındaki ilişkiye aracı değişken olarak dâhil edilmiştir. Kurulan aracılık modelinde demokratik okul kültürü algısı ile okul bağlılığı arasındaki anlamlı ilişkide yol katsayısı 0.72 $(t=11.45, p<0.05)$; okul bağlılığı ile akademik isteklilik arasındaki anlamlı ilişkide yol katsayısı .91 $(t=8.31, p<0.05)$ olarak hesaplanmıştır. Ancak demokratik okul kültürü algısı ile akademik isteklilik arasındaki doğrudan etki istatistiksel olarak anlamsızlaşmıştır. Başka bir ifadeyle ölçüm modelinde bu iki değişken arasındaki anlamlı ilişkinin, aracılık modelinde 0.12 düzeyindeki yol katsayısıyla, istatistiksel olarak anlamsız olduğu görülmüştür ( $t=1.82$, p>0.05). Modele ilişkin uyum iyiliği değerleri (Bkz. Tablo 4) ve yol katsayıları demokratik okul kültürü ile akademik isteklilik arasındaki ilişkide, okul bağlılığının tam aracılık etkisi 
olduğunu göstermiştir. Nitekim Şimşek’e (2007) göre, ölçüm modelinde bağımsız ve bağımlı değişken arasındaki ilişki katsayısı aracı değişkenin test edildiği modelde düşüyor veya istatistiksel olarak anlamsızlaşıyorsa, bu durum ilgili değişkenin aracılık etkisi gösterdiğini ifade etmektedir.

Tablo 4. Ölçüm ve Aracılık Modellerine ait Uyum İyiliği Değerleri

\begin{tabular}{|c|c|c|c|}
\hline Ölçüm Modeli & $\begin{array}{r}\text { Uyum iyiliği } \\
\text { de气̆grleri }\end{array}$ & Aracılık Modeli & $\begin{array}{r}\text { Uyum iyiliği } \\
\text { değerleri }\end{array}$ \\
\hline $\begin{array}{r}D O K \leftrightarrow O B^{*} \\
\mathrm{OB} \leftrightarrow A I^{*} \\
D O K \leftrightarrow A I^{*}\end{array}$ & & $\begin{array}{r}D O K \rightarrow O B^{*} \\
\text { OB } \rightarrow A I^{*} \\
\boldsymbol{D O K} \rightarrow \boldsymbol{A} \dot{\boldsymbol{I}}\end{array}$ & \\
\hline$\chi^{2}$ & 2415.37 & $\chi^{2}$ & 2506.51 \\
\hline$d f$ & 514 & $d f$ & 515 \\
\hline$\chi^{2} / d f$ & 4.69 & $\chi^{2} / d f$ & 4.86 \\
\hline RMSEA & 0.07 & RMSEA & 0.07 \\
\hline$R M R$ & 0.05 & $R M R$ & 0.05 \\
\hline AGFI & 0.80 & AGFI & 0.80 \\
\hline CFI & 0.97 & CFI & 0.97 \\
\hline GFI & 0.85 & GFI & 0.85 \\
\hline NFI & 0.97 & $N F I$ & 0.96 \\
\hline
\end{tabular}

Tablo 4'deki modellere dayalı olarak aracılık etkisi doğrulanan okul bağlılığının, değişkenler arasındaki aracılılık rolünün tekrar sınanması için yapılan sobel testi sonuçları ise Tablo 5'te sunulmuştur.

Tablo 5. Okul Bağlılığının Aracılık Etkisinin Anlamlılığını Gösteren Sobel Test Sonucu

\begin{tabular}{|c|c|c|c|c|c|c|}
\hline \multicolumn{3}{|c|}{ Bağımsız Değişken } & $\boldsymbol{\beta}$ & Aracı Değişken & $\boldsymbol{\beta}$ & Bağımlı Değişken \\
\hline \multicolumn{3}{|c|}{ Demokratik Okul Kültürü } & 0.72 & Okul Bağlılı̆̆1 & 0.91 & Akademik İsteklilik \\
\hline Sobel & $\mathrm{z}$ & $\mathrm{p}$ & & & & \\
\hline Test & 6.725 & 0.000 & & & & \\
\hline
\end{tabular}

Tablo 5’te görüldüğü üzere sobel analizine ait z değerleri ve anlamlılık düzeyi, okul bağlılığının, demokratik okul kültürü ile akademik isteklilik arasında aracılık etkisinin olduğunu göstermiştir $\left[\left(\mathrm{Z}_{\text {sobel }}=6.725, \mathrm{p}<0.05\right)\right]$.

\section{Tartışma}

Bu araştırmada demokratik okul kültürü, okul bağlılığı ve akademik isteklilik arasındaki ilişkiler keşfedilmiş; demokratik okul kültürü ile akademik isteklilik arasındaki ilişkide okul bağlılığının aracılık etkisinin olup olmadığı belirlenmiştir. Bu bağlamda öncelikle bu üç 
değişken ve boyutlarına ilişkin betimsel analiz sonuçları incelenmiş sonrasında aralarındaki ilişkilere yönelik dört hipotez test edilmiştir.

Araştırmada lise öğrencilerinin demokratik okul kültürüne ilişkin algılarının orta derecede katılıyorum düzeyinde olduğu görülmüştür. Ortalamaların orta düzeyde olması, okullarda demokratik okul kültürüne yönelik kimi eksikliklerin olduğuna işaret etmektedir. Örneğin madde ortalamaları, okulda öğrencilerle ilgili kararlar alınırken onların görüşlerinin ve kararlara yönelik itirazlarının dikkate alınması, öğrencilerin kendi haklarını savunurken desteklenmesi ve cesaretlendirilmesi, ayrım gözetilmeksizin her öğrenciye eşit muamele yapılması gibi konulardaki öğrenci algılarının görece olumsuz olduğunu göstermiştir. Bu araştırma bulgusu ile paralel olarak öğrencilerinin demokratik okul kültürü algılarının belirlendiği bir çalışmada iletişim, etkileşim, işbirliği, okul ve öğrenme ortamına yönelik ortalamaların orta düzeyde olduğu, karar süreçlerine katılıma yönelik görüşlerin en düşük ortalamaya sahip olduğu belirlenmiştir (Yavuz -Tabak, 2017). Başka bir araştırmada ise Argon ve İsmetoğlu (2016), lise öğrencilerinin okul yaşam kalitesi hakkındaki en olumsuz duygularının okul yönetimi boyutu ile ilişkili olduğunu; okul yönetiminde kararlara katılım/katılımcılık, iletişim biçimleri/kendini rahatça ifade etme, tüm öğrencilerin sorunlarına yönelik duyarlılık gösterilmesi gibi konularda sorunlar yaşandı̆̆ını ortaya koymuşlardır. Aynı ölçeğin kullanıldığı başka bir çalışmada Sarı, Ötünç ve Erceylan (2007) da okuldaki demokratik kültürü yansıtan okul yönetimi boyutuna ait ortalamanın istenen düzeyde olmadığını belirtmişlerdir. Lise öğrencilerinin okullarında yaşadığı problemleri belirleyen Erdener, Sezer ve Tezci (2017) ise, okulların çok katı bir disipline sahip olduğuna, ders programlarının ve sınavların öğrencilere uygun olmayacak şekilde ayarlandığına, öğretmen ve okul yöneticilerinin öğrencilerle iletişimlerinde anlayışsız olduklarına ve onlara hakaret ettiklerine yönelik görüşlerin olduğunu ortaya çıkarmışlardır. Öğrenciler tarafından algılanan böylesi sorunların, demokratik bir okul kültürü ile bağdaşmadığını söylemek mümkündür. Ayrıca liselerde demokratik okul kültürü yaratmada öğrencilerini gelişim özelliklerini de dikkate almak, demokratik bir yaşama yönelik duyarlılıklarını göz önünde bulundurmak gerekmektedir. Nitekim Avcı (2006) ergenlik döneminde olan öğrencilerin özerklik, özgürlük, haklar, görevler ve sorumluluklara ilişkin toplumsal değer yargılarını, içinde bulundukları karmaşık psikolojik süreç içinde oluşturmaya çalıştıklarını ifade etmektedir. Gül ve Güneş (2009) ise ergenlerin toplumsal değerler, ahlak ve etik konularında önceki dönemlere göre çok daha fazla hassasiyet gösterme eğiliminde olduklarını belirtmektedir. Dolayısıyla lise öğrencilerindeki demokratik okul kültürü algılarının bu dönemin gelişim özelliklerinden dolayı da daha duyarlı olduğunu 
bilmek, okullarda böylesi bir kültürü yaratmada öğrenci istek, ilgi ve ihtiyaçlarını dikkate almanın, bu dönem öğrencileri için oldukça önemli olduğunu bilmek gerekmektedir. Bu da okulların kendi etkinlik ve uygulamalarını eleştirel bir gözle değerlendirmeleri, okuldaki yerel kararlara öğrenci-öğretmen-veli katılımlarını -mümkün olduğunca- sağlamaları, okuldaki katılımcı ve demokratik anlayış kültürüne yönelik eksiklikleri düzeltmeleri ile mümkün görünmektedir.

Öğrencilerin okul bağl1lıklarına bakıldığında genel ortalama puanın orta düzeyde katılıyorum seviyesinde olduğu tespit edilmiştir. Yapılan farklı araştırmalarda da lise öğrencilerin okul bağl1lıklarının genellikle düşük orta düzey ya da orta düzeyde olduğu tespit edilmiştir (Arastaman, 2009; Arastaman ve Yüner, 2020; Argon ve İsmetoğlu, 2016; Kalayc1 ve Özdemir, 2013; Özdemir, 2017). İlgili araştırmalar, bu araştırma bulgularıyla örtüşmektedir. Ortaöğretim kurumlarında okul bağlılı̆̆ının istenen düzeyde olmaması, demokratik değerlere yönelik hassas ve meslek seçimi açısından stresli bir dönemde olan lise öğrencilerinin, okul ortamına yönelik isteklerinin tam olarak karşılanamadığına işaret etmektedir. Okul bağlılığı düzeyine ilişkin dikkat çekici bir bulgu da öğrencilerin davranışsal bağlllıklarının -istenen düzeyde olmasa da- diğer boyutlara göre yüksek olması, buna rağmen bilişsel ve duyuşsal bağlılıklarının düşük olmasıdır. Bu durum, kültürel etmenlerle de açıklanabilir. Daha açık bir ifadeyle Türkiye'de öğrencilerin otorite olarak kabul ettiği konumlardan gelen görev sorumlulukları ne olursa olsun yerine getirme eğiliminde oldukları çıkarımında bulunulabilir. Benzer şekilde belirsiz durumlardan uzaklaştıran ve düzeni sağlayan her türlü kuralı kabullenme eğilimi gösterebilecekleri de düşünülebilir. Nitekim Terzi (2004) öğrencilerin belirsizlikten kaçma ve güç mesafesi algısının sırasıyla çok ve orta düzey bir ortalamaya sahip olduğunu bulgulamıştır. Bu kültürel özellik, öğrencilerin davranışsal bağl1lıklarının, diğer bağlılık türlerine oranla daha yüksek çıkmasına neden oluyor olabilir. Bu çerçevede Finn ve Voelkl da (1993) disiplin kurallarının davranışsal bağlılık üzerinde önemli bir rol oynamadığını sonucuna ulaşmıştır. $\mathrm{Bu}$ aslında disiplin kurallarının davranışsal bağlılığı negatif yönde etkilemediğine işaret etmektedir. $\mathrm{Bu}$ da öğrencilerin disiplin kurallarını kendi düzenlerini sağlayan ve belirsiz durumlara karşı onları koruyan ilkeler bütünü olarak algılamalarından kaynaklanıyor olabilir. Dolayısıyla lise öğrencilerinin duyuşsal ve bilişsel bağlılıklarının, davranışsal bağlılıklarından daha düşük çıkıyor olmasının altında yatan nedenlerden biri, öğrencilerin kültürel özellikleri ve disiplin kurallarına bakış açıları ile ilişkili olabilir.

Araştırmanın üçüncü değişkeni olan akademik isteklilik ortalamasının, orta seviyede katılıyorum düzeyinde olduğu tespit edilmiştir. Arastaman ve Özdemir (2019) da yaptıkları bir 
çalışmada akademik istekliliğin orta düzeyde olduğunu saptamışlardır. Hâlbuki yüksek düzeyde bir akademik isteklilik, liseden sonra mesleki yönelimler açısından önemli bir eğitim kademesi olan üniversiteye giriş için oldukça önemlidir. Akademik isteklilikle ilgili dikkat çeken başka bir bulgu da yükselme isteği, başarı güdüsü ve okula yönelik önem boyutları orta düzeyde katılıyorum ile katılıyorum puan aralığında bir ortalamaya denk gelmekteyken; okuldan ve yaşamdan keyif alma ve okula yönelik ilham boyutları katılmıyorum ile orta düzeyde katılıyorum puan aralığına denk gelmektedir. Başka bir ifadeyle akademik istekliliğe yönelik ortalamayı düşüren iki boyut okul yaşamı ve okuldan ilham alma ile ilişkilidir. Bu durum yine Arastaman ve Özdemir (2019) tarafından yapılan çalışma bulgularılyla benzerlik göstermektedir. Lise öğrencilerinin okul yaşam kalitesine yönelik algılarının ortaya çıkarıldığ 1 çalışmalardan birinde öğrencilerin en az memnun oldukları konuların -okul yaşamında keyif alma düzeylerinin belirleyicileri olarak kabul edilebilecek- okul yönetimi, öğretmen davranışları ve okuldaki sosyal etkinlikler olduğu tespit edilmiştir (Argon ve İsmetoğlu, 2016). Yine benzer bir çalışmada lise öğrencilerinin okula yönelik olumlu duyguların, diğer boyutlara göre daha düşük ortalamaya sahip olduğu belirlenmiştir (Sarı ve diğ., 2007). Halbuki akademik istekliliğin göstergelerinden biri, büyük ölçüde eğitimine devam etme isteği gibi uzun dönemli çıktılarla ifade edilmektedir (Redd ve diğ., 2001; Smith ve diğ., 2016). Bu nedenle okul yaşam kalitesine ilişkin geliştirilen olumsuz tutumların, akademik istekliliğin okul yaşamından keyif alma ve okula yönelik ilham boyutlarında sorunlara yol açabileceği, öğrencilerin eğitimlerine devam etme isteklerini kırabileceği söylenebilir.

İlk hipotezin doğrulandığı analiz sonuçlarına göre demokratik okul kültürü algısının, okul bağlılığının anlamlı bir yordayıcısı olduğu sonucuna ulaşılmıştır. Okula bağlılık gösterme, öğrencilerin okulda kendilerini mutlu ve güvende hissetme, yapılan faaliyetlere zorla değil içsel bir coşkuyla katılım gösterme eğilimleri ile ilişkilendirilmektedir (Fredricks ve diğ., 2005). Böylesi bir okul bağlılığının ise ancak okul toplumu arasındaki ilişkilerin demokrasi, saygı ve güvene dayalı olduğu bir okul kültürü ile sağlanabileceği düşünülebilir. Demokratik bir okul kültürü ise sosyal ilişkilerin gücü, kararlara katılım, farkl1/yeni fikirlerin desteklenmesi, farklılıkların kabulü, sosyal destek, öğrenci ihtiyaçlarının önemsenmesi ile ölçülmektedir. Nitekim Cemalcılar (2010) tarafından yapılan bir çalışmada öğrencilerin öğretmenleriyle, okul yöneticileriyle ve arkadaşlarıyla kurdukları sosyal ilişki kalitesinin, onların okul bağlılığı üzerinde rol oynadığı belirlenmiştir. Leithwood ve Jantzi (2000) ise olumlu okul kültürünün, okuldaki sosyal ağların ve ilişkilerin okul bağlılığı üzerinde önemli etkileri olduğunu saptamışlardır. Diğer çalışmalar öğrencilerin yeni fikirler ortaya koymalarına olanak sağlayan, 
sosyal desteğin güçlü olduğu, öğrenme yaşantıları için öğrenci ihtiyaçlarının sorulduğu bir öğrenme ortamı ile okul bağlılığı arasında anlamlı ilişkilerin olduğunu göstermiştir (Bilgin ve Taş, 2018; Yavrutürk, 2019). Benzer şekilde öğrencilerin destekleyici öğretmen davranışlarına, okul yönetimine ilişkin memnuniyetlerine ve okulda kendi statülerine yönelik kalite algıları ile okul bağlılıkları arasında da anlamlı ilişkiler tespit edilmiştir (Argon ve İsmetmoğlu, 2016). Bu araştırma bulguları demokratik okul kültürü ile okul bağlılığı arasındaki ilişkiyi destekler nitelikte sonuçlar sunmaktadır. Bunların yanında demokratik bir okul kültürünün en önemli göstergelerinden biri o okul içerisindeki sosyal adalet anlayışıdır (Møller, 2006). Okullardaki sosyal adalet uygulamaları ise öğrencilerin okula bağlılıklarını sağlayan önemli unsurlardan biridir (Özdemir, 2017). Nitekim Dewey (1916), demokratik bir okul ortamında eğitimin öğrencileri, aralarında hiçbir fark gözetilmeksizin özgürleştirmesi ve bağımsızlaştırması gerektiği üzerinde durmaktadır. Bu bağlamda, ancak böyle bir ortamda öğrenci okul toplumu ile bütünleşebilecek ve okuluna bağl11ık gösterebilecektir.

Araştırmanın ikinci hipotezi kapsamında, demokratik okul kültürü algısının, akademik istekliliğin anlamlı bir yordayıcısı olduğu tespit edilmiştir. Dewey (1916) öğrencilerin, ancak demokratik toplum değerlerinin yaşatılıp öğretildiği bir eğitim ortamında deneyimlerini sınırlandırmadan ortaya koyabileceklerini ifade etmekte; kendisini demokratik bir okul yaşamında güvende hisseden öğrencilerin başarılı fikirler üretebileceklerini belirtmektedir. Bununla birlikte Şişman, Güleş ve Dönmez (2010) demokratik bir okul ortamında öğrenim gören öğrencilerin üretken ve sorumluluk duygusu gelişmiş bireyler olacakları ifade edilmektedir. Dolayısıyla ancak demokratik bir okul kültürü sayesinde öğrencilerin kendi deneyimleri ile başarı duygusu tatmalarına olanak sağlanabilecektir. $\mathrm{Bu}$ da onları başarıya götürecek ve akademik anlamda daha istekli, daha azimli bireyler haline getirebilecektir. Nitekim bu konuda yapılan ampirik çalışmalarda da öğrencilerdeki akademik istekliliğinin, okul iklimi, öğrenciler ve öğretmenler arasında kurulan iletişim gibi okul düzeyli demokratik okul kültürüne dayalı değişkenlerden etkilendiği tespit edilmiştir (Pascarella, 1984; Plucker, 1998). Bu bağlamda öğrencilerin akademik ve diğer yönlerden başarısını temel alan okul etkililiğinin sağlanmasında, okul liderinin okul toplumu ile sürekli işbirliği halinde olması ve onları okul karar süreçlerine dâhil edebilmesi büyük önem taşımaktadır (Gümüşeli, 2001). Böylesi bir okul yönetim anlayışı öğretmenlere de yansıyacak; okul yönetimindeki demokratik anlayışı sınıf yönetimlerine taşıyan öğretmenlerin öğrencileri, daha başarılı ve istekli olabileceklerdir (Arslan, 2012). Çünkü ancak demokratik bir sınıf ortamında öğrencilerin öğrenme sürecine aktif katılımları sağlanabilecektir. Bununla birlikte hiçbir ayrım 
gözetilmeksizin tüm öğrencilere eşit bir hoşgörü ile yaklaşılan sınıflarda, öğrencilerin görüşlerini korkmadan ifade edebilmesi, görev üstlenerek sorumluluk alması ve anlamlı öğrenme yaşantılarına sahip olması mümkün olabilecektir (Duman ve Koç, 2004).

Üçüncü hipotez testi kapsamında okul bağlılığının, akademik istekliliğin anlamlı bir yordayıcısı olduğu bulunmuştur. Literatürde okul bağlılı̆̆ı üzerine yapılan ampirik çalışmalar ve incelemeler, bu çalışma bulgusunu destekler niteliktedir. Örneğin Osterman (2000) okul bağlılı̆̆ı yüksek olan öğrencilerin, akademik çabalarının, motivasyonlarının ve öğrenme yaşantılarına verdikleri önemin yüksek olacağını, bunun da akademik başarılarına yansıyacağını ifade etmektedir. Buna paralel olarak çalışmalar, okul bağglılı̆̆ ile akademik isteklilik, akademik motivasyon ve başarı arasında anlamlı ilişkiler olduğunu göstermiştir (Chase, Hilliard, Geldhof, Warren ve Lerner, 2014; Özdemir, 2015; Veiga ve diğ., 2014). Erdoğdu ve Yüzbaş (2018), daha yüksek ortalamaya sahip olan öğrencilerin okul bağlılıklarının daha yüksek olduğunu saptamışlardır. Finn ve Rock (1997) ise okul bağlılığı ile yüksek akademik çaba arasındaki ilişkiye dikkat çekmişlerdir. Bu bağlamda Wang ve arkadaşları (1997), öğrencilerin okul başarılarına ve psikososyal iyi oluşlarına katkı sağlayan okul çaplı uygulamalardan birini, öğrencilerin okul yaşantısına olan bağlılıklarını geliştirme olarak ifade etmişlerdir. Nitekim akademik istekliliğin arttırılması önündeki en büyük engellerden biri okul dışındaki çeldiriciler ve güçlü çevre etkileri olarak görülmektedir (Smith ve diğg., 2016). Bu nedenle öğrencilerin okulda istekle geçirdikleri kaliteli zamanın arttırılmasına ve bağlılıklarının geliştirilmesine yönelik okul çaplı çalışmalar, onların akademik istekliliklerini arttıran önemli etmenler arasında sayılabilir.

Araştırmanın ana hipotezi olan dördüncü hipotezin test edilmesi için yapılan analizler ise, demokratik okul kültürü ile akademik isteklilik arasındaki ilişkide okul bağl1lığının aracılık etkisi olduğunu göstermiştir. Alanyazında okul müdürünün liderlik davranışlarının öğrenci başarısı üzerinde, iş birlikçi kültür oluşturma, okul yaşam koşullarını geliştirme, öğretmenler arası kolektif yeterliği geliştirme gibi değişkenlerin aracı etkisiyle dolaylı etkilerinin olduğuna kanıtlar sunan çalışmalar bulunmaktadır (Day, Gu ve Sammons, 2016; Fancera ve Bliss, 2011). Bununla birlikte okul yöneticilerin liderlik davranışlarının, olumlu okul iklim özellikler yaratma ve okuldaki işleyişi düzenleme üzerinden öğrenci başarısında dolaylı olarak etkisinin olduğunu göstermektedir (Özdemir ve Yalçın, 2019). Bu çalışmalar okul yöneticilerinin oluşturacağ 1 demokratik bir okul kültürünün de, öğrencilerin akademik isteklilik ve başarıları üzerinde dolaylı etkilerinin olabileceğine kanıtlar sunmaktadır. Nitekim bu çalışmada okul 
yöneticilerinin oluşturduğu demokratik okul koşullarının, öğrenci bağlılığını arttırma yoluyla, okul başarıları üzerinde etkili olduğu tespit edilmiştir.

Araştırmanın ana hipotezi kapsamında düşünüldüğünde, öğrencilere sağlanan demokratik yaşam koşulları, kendilerini rahat ifade etmelerine, psikolojik iyi oluşlarına ve okula ilişkin olumlu duygu geliştirmelerine katkı sağlayacak; okulun değerli ve önemli bir bireyi olduğuna yönelik inançlarını güçlendirecektir. Bu inanç ve olumlu duygular, onların okula bağlı bireyler olmasında ve okulun gereklerini yerine getirmesinde itici bir olacaktır. Örneğin Roeser, Midgley ve Urdan (1996) okuldaki iletişim ve ilişkilerin, okul bağlılı̆̆ı; okul bağlılığının da akademik başarı üzerinde rol oynadığını tespit etmişlerdir. Benzer şekilde öğrencilerin sınıf içine yansıyan sosyal/duygusal iklim, öğretmen-öğrenci arası ilişki ve ihtiyaçlarını karşılayan öğretim kalitesinin, onların psikolojik ve davranışsal bağlılıkları üzerinde etkili olduğu; bağlılığın da akademik başarı üzerinde rol oynadığı tespit edilmiştir (Dotterer ve Lowe, 2011). İlgili çalışmalar da, demokratik okul kültürünün okul bağl1lığ1 üzerinden öğrencilerin akademik istekliliklerine katkı sağladığına ilişkin hipotezi destekler nitelikte kanıtlar sunmaktadır. Tüm bu bulguların desteklendiği başka bir çalışmada ise Day ve Leithwood (2007), sosyo-ekonomik ve kültürel açıdan farklılıklar gösterse de kalıcı bağlılığın ve öğrenci başarısının yüksek olduğu okullardaki ortak özellikleri belirlemişlerdir. Bu okulların öğrenci haklarına, sosyal adalete ve demokratik ilkelere dayandığını, okulda açık bir iletişim olduğunu, kapsayıcı anlayışla tüm öğrencilere yüksek beklenti geliştirildiğini ifade etmişlerdir. Görüldüğü üzere okul yöneticilerinin demokratik bir okul kültürü oluşturmaları ve öğretmenleri de destekleyerek bu kültürü sınıflarına taşımalarını sağlamaları gerekmektedir. Başka bir ifadeyle yöneticilerin ve öğretmenlerin demokratik bir okul kültürü inşa etmeleri, demokrasiyi yaşatacak yapı ve süreçler yaratmaları ile ilişkilidir (Beane and Apple, 2007). Yaratılacak bu yap1 ve süreçler, özellikle de hak, hürriyet, özgürlük, demokrasi gibi konularda hassas bir geçiş döneminde olan lise öğrencilerinin okul bağlılı̆̆ı ve akademik isteklilikleri açısından büyük önem taşımaktadır.

\section{Sonuç ve Öneriler}

Hem gelişimsel hem de hayata atılma anlamında kritik bir dönemde olan lise öğrencilerinin akademik isteklilikleri, onların seçecekleri üniversite ya da yaşam boyu devam etmek istedikleri mesleki yönelimler açısından oldukça büyük önem taşımaktadır. Akademik istekliliğin arttırılması ise öğrencilerin okula bağlılık geliştirmelerine olanak tanıyan demokratik okul koşulları ile mümkün görünmektedir. Nitekim lise öğrencilerinin akademik 
istekliliklerinin öncüllerinin araştırıldığg bu araştırmada, demokratik okul kültürünün okul bağlılığg aracılığıyla öğrencilerin akademik isteklilikleri üzerinde rol oynadığı tespit edilmiştir.

Türkiye gibi eğitim politikalarının merkeziyetçi bir anlayışla belirlendiği ülkelerde, kimi kararlara öğrenci katılımının sağlanması önünde engeller ve sınırlılıklar bulunmaktadır. Mevcut sınırlılıkların yanında eğitim anlayışında katılımcılık, eğitime erişim ve sosyal adalet, kapsayıcılık gibi kavramlara ilişkin çalışmalar gelişim göstermekte; okul düzeyli demokratik yaşam koşulları giderek daha da önem taşımaktadır. Bu koşulları, okul düzeyli etkinlik ve uygulamalara aktif katılım, açık iletişim, okul olanaklarına eşit erişim ve sosyal ayrımcılığın engellenmesi, azınlık haklarına ve bütünlüğe saygı, kapsayıcı eğitim, bireye değil topluluğa odaklanma ve çeşitliliği zenginlik olarak görme şeklinde ifade etmek mümkündür. Bununla birlikte okul etkinliklerinde sosyal değerlerin önemine vurgu, desteğe ve karşıl1klı güvene dayalı ilişkiler, lider-öğretmen-öğrenci birlikteliği de demokratik bir okul kültürü yaratmanın genel koşulları arasında sayılmaktadır. Öğrenciler ancak bu koşullarda okullarına bağlılık geliştirebilmekte ve kendilerini okulun bir parçası olarak görebilmektedir. Okuluna içten bağl1lık geliştiren öğrenciler ise hedef belirleme, o hedefe doğru sebatla çalışma, okul etkinliklerini içsel bir motivasyonla yapma ve okulundan başarıyla mezun olma isteği bakımından daha aktif ve eyleme dönük davranışlar gösterebilmektedirler. Başka bir ifadeyle okula bağlı olan öğrencilerin akademik istekliliğe yönelik eğilimleri de artmaktadır.

Elde edilen bu sonuçlar 1şığında okul müdürlerinin demokratik bir okul kültürü yaratmada gerekli koşulları sağlamaları, öğretmenleri demokratik sınıf yönetimi konusunda teşvik etmeleri önerilmektedir. Ancak bu teşvik, demokratik yaşam koşullarını anlatmakla değil, bizzat uygulama, rol model olma ve tüm okul toplumuna demokratik bir okul yaşantısı sunma yoluyla gerçekleşebilecektir. Bu bakımdan okul yöneticilerinin ve öğretmenlerin demokratik bir okul ve sınıf yaşantısı için gerekli koşulları yerel düzeyde tespit etmeleri, öğrencilerin bu konudaki ilgi, ihtiyaç ve isteklerini dikkate almaları; sonrasında da bunları hayata geçirip sürekliliğini sağlamaları önerilmektedir. Bu nedenle hem öğretmen hem okul yöneticilerine verilen hizmet içi eğitimlere, demokratik okul kültürü ve okul yaşantısına öğrencinin aktif katılımının sağlanmasına yönelik farkındalık geliştirecek konular eklenebilir. Demokratik okul kültürü ancak ve ancak süreklilik gösterdiği ve bir yaşam biçimi haline geldiğinde gerçekçi bir yapıya ulaşacaktır.

$\mathrm{Bu}$ araştırma lise öğrencileri ile gerçekleştirilmiş, akademik istekliliğin arttırılmasında demokratik okul kültürünün rolü üzerinde durulmuştur. Yapılacak diğer araştırmalarda, akademik istekliliği arttıran farklı öncüllerin çalışılması ve bu çalışmaların nitel araştırmalarla 
YYÜ Eğitim Fakültesi Dergisi (YYU Journal of Education Faculty), 2020; 17(1):959-990,http://efdergi.yyu.edu.tr,

desteklenerek detaylandırılması alana katkı sağlayacaktır. Ayrıca öğrencilerin okul bağl1lıklarını geliştiren diğer yönetsel etmenler de yapılacak nitel araştırmalar yoluyla ortaya çıkarılabilir. Bu bağlam içinde sadece lise öğrencileri değil, diğer kademelerle de aynı çalışmaların yürütülmesi alana katkı sağlayabilecektir.

\section{Makalenin Bilimdeki Konumu}

Eğitim Bilimleri Bölümü/Eğitim Yönetimi

\section{Makalenin Bilimdeki Özgünlüğü}

Literatürde lise öğrencilerinin akademik istekliliklerinin arttırılmasında dışsal faktörlerin önemli olduğu vurgulanmaktadır. Ancak öğrencilerin akademik istekliliklerini geliştirebilecek dişsal bir faktör olarak demokratik bir okul yönetiminin, öğrencilerin akademik isteklilikleri üzerinde nasıl ve ne düzeyde bir rol oynayabileceğinin belirlenmesine yönelik herhangi bir çalışmaya rastlanamamıştır. Bu nedenle çalışmada, demokratik okul kültürünün, okul bağlılığını geliştirme yoluyla akademik isteklilik üzerinde rol oynayıp oynamadığı üzerinde durulmuştur.

\section{Kaynaklar}

Altınkurt, Y. (2008). The reasons for students irregular attendance and the effect on this students irregular attendance on their academic achievement. Journal of Sociel Science, 20, 129-142.

Appleton, J. J., Christenson, S. L., Kim, D. \& Reschly, A. L. (2006). Measuring cognitive and psychological engagement: Validation of the student engagement instrument. Journal of School Psychology, 44, 427- 445.

Arastaman, G. \& Özdemir, M. (2019). Lise öğrencilerinin görüşlerine göre akademik isteklilik, akademik benlik yeterliği ve kültürel sermaye arasındaki ilişki. Eğitim ve Bilim, 44(197), 105-119.

Arastaman, G. (2009). Lise birinci sınıf öğrencilerinin okula bağlılık durumlarına ilişkin öğrenci, öğretmen ve yöneticilerin görüşleri. Pamukkale Üniversitesi Eğitim Fakültesi Dergisi, 26, 102-112.

Arastaman, G. \& Yüner, B. (2019). Kamu ve özel lise öğrencilerinin okul bağl1lıklarının bazı değişkenlere göre incelenmesi. Türk Ĕ̆itim Bilimleri Dergisi, 17(2), 258-284.

Argon, T. \& İsmetoğlu, M. (2016). Öğrencilerin lise yaşam kalitesi algıları ile okula bağlılık düzeyleri arasındaki ilişki. Ĕ̆itim ve Öğretim Araştırmaları Dergisi, 5, 238-249. 
YYÜ Eğitim Fakültesi Dergisi (YYU Journal of Education Faculty), 2020; 17(1):959-990,http://efdergi.yyu.edu.tr,

Arslan, M. C. (2012). İlköğretim okul müdürlerinin demokratik tutum ve davranışlarının ögrretmen motivasyonu ve ögrenci başarısına etkisi. Yayınlanmamış yüksek lisans tezi, Gaziantep Üniversitesi, Gaziantep.

Atalay-Kabasakal, K., Göçer-Şahin, S., Kelecioğlu, H., Gelbal, S., Atar, B. \& Doğan, N. (2015). Lise öğrencilerinin demokratik okul kültürü algılarının incelenmesi. Kuram ve Uygulamada Eğitim Yönetimi, 21(2), 247-270.

Avcı, M. (2006). Ergenlikte toplumsal uyum sorunları. Ankara Üniversitesi Sosyal Bilimler Enstitüsü Dergisi, 7(1), 39-63.

Avery, C. \& Turner, S. (2012). Student loans: Do college students borrow too much - or not enough. Journal of Economic Perspectives, 26(1), 165-192.

Bäckman, E. \& Trafford, B. (2007). Democratic governance of schools. Strasbourg: Council of Europe.

Beane, J. A. \& Apple, W. M. (2007). The case for democratic schools. Harwey Daniels (Edt), Democratic Schools: Lessons in Powerful Education içinde. (s.1-29), Portsmouth NH: Heinemann.

Bickmore, K. (2001). Student conflict resolution, power "sharing” in schools, and citizenship education. Curriculum Inquiry, 31(2), 137-162.

Bilgin, O. \& Tas, I. (2018). Ergenlerde okula bağlılığın yordayıcıları olarak okul iklimi ve sosyal medya bağımlılı̆̆ı. Akdeniz Ĕ̈itim Araştırmaları Dergisi, 12(26), 15-33.

Cemalcilar, Z. (2010). Schools as socialisation contexts: Understanding the impact of school climate factors on students: Sense of school belonging. Applied Psychology, 59, 243.

Chan, R. Y. (2016). Understanding the purpose of higher education: An analysis of the economic and social benefits for completing a college degree. Journal of Education Policy, Planning and Administration (JEPPA), 6(5), 1-40.

Chase, P. A., Hilliard, L. J., Geldhof, G. J., Warren, D. J. \& Lerner, R. M. (2014). Academic achievement in the high school years: The changing role of school engagement. Journal of Youth and Adolescence, 43(6), 884-896.

Çengel, M., Totan, T. \& Çöğmen, S. (2017). Okula Bağl1lık Ölçeğinin Türkçeye uyarlanması. Abant İzet Baysal Üniversitesi Eğitim Fakültesi Dergisi, 17(4), 1820-1837.

Day, C. \& Leithwood, K. (2007). Building and sustaining successful principalship: Key themes. C. Day \& K. Leithwood (Eds.), Successful principal leadership in times of change: An international perspective. içinde (171-188). Dordrecht, UK: Springer. 
YYÜ Eğitim Fakültesi Dergisi (YYU Journal of Education Faculty), 2020; 17(1):959-990,http://efdergi.yyu.edu.tr,

Day, C., Gu, Q. \& Sammons, P. (2016). The impact of leadership on student outcomes: How successful school leaders use transformational and instructional strategies to make a difference. Educational Administration Quarterly, 52(2), 221-258. doi:10.1177/0013161x15616863

Demir, K. \& Akman-Karabeyoglu, Y. (2015). Factors associated with absenteeism in high schools. Eurasian Journal of Educational Research, 62, 37-56.

Dewey, J. (1916). Democracy and education: An introduction to the philosophy of education. Newyork: Macmillan.

Dotterer, A. M. ve Lowe, K. (2011). Classroom context, school engagement, and academic achievement in early adolescence. Journal of Youth and Adolescence, 40(12), 1649-1660.

Duman, T. \& Koç, G. (2004). Eğitim fakültesi öğrencilerinin ögretim elemanlarının demokratik tutum ve davranışlarına ilişkin görüşleri. XIII. Ulusal Eğitim Bilimleri Kurultayı. İnönü Üniversitesi Eğitim Fakültesi, Malatya.

Elitok-Kesici, A. \& Yengin-Sarpkaya, P. (2013). Lise öğrencilerinin sınıf içi istenmeyen davranışları. Turkish Studies, 8(12), 467-478.

Erdener, M. A., Sezer, F. \& Tezci, E. (2017). Liselerde sık karşılaşılan öğrenci problemleri. Turkish Studies, 12(14), 151-166.

Erdoğdu, M. Y. \& Yüzbaş, D. (2018). Lise öğrencilerinin okula bağl1lık ile genel öz-yeterlilik düzeyleri arasındaki ilişki. Süleyman Demirel Üniversitesi Sosyal Bilimler Enstitüsü Dergisi, 32(3), 205-227.

Fancera, S. F. \& Bliss, J. R. (2011). Instructional leadership influence on collective teacher efficacy to improve school achievement. Leadership and Policy in Schools, 10(3), 349370.

Finn, J. D. \& Voelkl, K. E. (1993). School characteristics related to school engagement. Journal of Negro Education, 62, 249-268.

Finn, J. D. \& Rock, D. A. (1997). Academic success among students at risk for school failure. Journal of Applied Psychology, 82(2), 221-261.

Fredricks, J. A., Blumenfeld, P., Friedel, J. \& Paris, A. (2005). School Engagement. K. A. Moore \& L. H. Lippman (Eds.), What do children need to flourish? içinde (ss.305-321), New York: Springer.

Geckova, A., Tavel, P., Van Dijk, J., Abel, T. \& Reijneveld, D. (2010). Factors associated with educational aspirations among adolescents: cues to counteract socioeconomic 
YYÜ Eğitim Fakültesi Dergisi (YYU Journal of Education Faculty), 2020; 17(1):959-990,http://efdergi.yyu.edu.tr,

doi: $10.33711 /$ yyuefd.800885

Araştırma Makalesi

ISSN: 1305-2020

differences? BMC Public Health, 10(154). Erişim adresi: http://www.biomedcentral.com/1471-2458/10/154

Gölpek, F. \& Uğurlugelen, K. (2013). Entry systems of higher education in European countries and Turkey. Dicle University Journal of Economics and Administrative Sciences, 2(5), 64-77.

Gözübüyük T. M. (2011). Okulların demokratik ve katılımcı öğrenim ortamlarına dönüştürülmesi (Demokratik okul yönetimi). Milli Eğitim Dergisi, 192, 7-25.

Gül, S. K. \& Güneş, İ. D. (2009). Ergenlik dönemi sorunları ve şiddet. Sosyal Bilimler Dergisi, 11(1), 79-101.

Gül, S., Kıran, Ö. \& Nasirsi, H. (2016). Ortaöğretim (lise) öğrencilerinin devamsızlık nedenleri ve yeni ortaöğretim kurumları yönetmeliğinin öğrenci devamsızlıkları üzerindeki etkileri (Atakum ilçesi örneği). Uluslararası Sosyal Araştırmalar Dergisi, 9(44), 925-933.

Gümüşeli, A. İ. (2001). Çağdaş okul müdürünün liderlik alanları. Kuram ve Uygulamada Eğitim Yönetimi Dergisi, 28, 531-548.

Hecht, Y. \& Ram, Y. (2008). Dialogue in democratic education: From individual empowerment to social activism. Erişim adresi: https://www.scribd.com/document/237499152/TheDialogue-of-Democratic-Education

Helms, R. M. (2008). University admission worldwide. Education Working Paper Series Number 15. International Bank for Reconstruction and Development/ The World Bank, Washington, D.C. - USA.

Hooper, D., J. Coughlan, and M. R. Mullen. (2008). Structural equation modelling: Guidelines for determining model fit. The Electronic Journal of Business Research Methods, 6(1), $53-60$.

Işıkgöz, E. (2016). A study of democratic school culture perceptions of sport high school students. Educational Research and Reviews, 11(7), 491-498.

Jimerson, S. R., Campos, E. \& Greif, J. L. (2003). Toward an understanding of definitions and measures of school engagement and related terms. The California School Psychologist, $8(1), 7-27$.

Kalaycı, H. \& Özdemir, M. (2013). The influence of students’ perceptions toward quality of school life on their school engagement. GEFAD / GUJGEF, 33(2): 293-315.

Kaya, Y. K. (1996). Eğitim yönetimi kuram ve Türkiye'deki uygulama. Ankara: Bilim Yay.

Khattab, N. (2015). Students' aspirations, expectations and school achievement: what really matters? British Educational Research Journal, 41(5), 731-748. 
YYÜ Eğitim Fakültesi Dergisi (YYU Journal of Education Faculty), 2020; 17(1):959-990,http://efdergi.yyu.edu.tr,

Kızıldağ, S., Demirtaş-Zorbaz, S. \& Zorbaz, O. (2017). Lise öğrencilerinde okul bağlılığı. Eğitim ve Bilim, 42(189): 107-119.

Kline, R. B. (2011). Principles and practice of structural equation modeling. 3rd ed. New York: The Guilford Press.

Koçyiğit, M., Eğmir, E., \& Akçil, M. (2018). A glance at education and higher education from the perspective of high school senior students. MANAS Journal of Social Studies, 7(3), 119-141.

Krejcie, R. V. \& Morgan, D. W. (1970). Determining sample size for research activities. Educational and Psychological Measurement, 30, 607-610. doi:10.1177/001316447003000308.

Leithwood, K. A. \& Jantzi, D. (2000). The effects of transformational leadership on organizational conditions and student engagement with school. Journal of Educational Administration, 38(2), 112-129.

Lippman, L. \& Rivers, A. (2008). Assessing school engagement: A guide for out of school time program practitioners. Research to Results Child Trends, 39, 1 -5.

Louis, K. S. (2003). Democratic schools, democratic communities: Reflections in an international context. Leadership and Policy in Schools, 2(2), 93-108.

Møller, J. (2006). Democratic schooling in Norway: Implications for leadership in practice. Leadership and Policy in Schools, 5(1), 53-69.

Marks, H. M. (2000). Student engagement in instructional activity: Patterns in the elementary, middle, and high school years. American Educational Research Journal, 37, 153-184.

MEB-UNICEF. (2013). Ortaöğretimde sınıf tekrarı, okul terk sebepleri ve örgün eğitim dışında kalan çocuklar politika önerileri raporu. Erişim Adresi: http://www.meb.gov.tr/earged/unicef/S\%C4\%B1n\%C4\%B1f\%20Tekrar\%C4\%B1,\%20 Okul\%20Terki\%20Politika\%20Raporu.pdf

Morrison, K. A. (2008). Democratic classrooms: Promises and challenges of student voice and choice. Educational Horizons, 87(1), 50-60.

Newmann, F. (1981). Reducing student alienation in high schools: Implications of theory. Hardward Educational Review, 51, 546-564.

OECD. (2015). PISA 2015 results in focus. Erişim Adresi: https://www.oecd.org/pisa/pisa2015-results-in-focus.pdf

OECD. (2019). Programme for international student assessment (PISA) results from PISA 2018. Erişim Adresi: https://www.oecd.org/pisa/publications/PISA2018_CN_TUR.pdf 
YYÜ Eğitim Fakültesi Dergisi (YYU Journal of Education Faculty), 2020; 17(1):959-990,http://efdergi.yyu.edu.tr,

Osterman, K. F. (2000). Students' need for belonging in the school community. Review of Educational Research, 70(3), 323-367.

Önen, E. (2014). Öğrencinin okula bağl1lığı ölçeği: Türk ortaokul ve lise öğrencileri için uyarlama çalışması. Türk Psikolojik Danışma ve Rehberlik Dergisi, 5(42), 221-234.

ÖSYM. (2019). 2019-YKS Sinav Sonuçları. Erişim adresi: https://dokuman.osym.gov.tr/pdfdokuman/2019/YKS/sayisalbilgiler18072019.pdf

Özdemir, M. (2017). Sosyal adalet liderliği, okula yönelik tutum ve okul bağl1lı̆̆ arasındaki ilişkilerin incelenmesi. Eğitim ve Bilim, 42(192), 267-281.

Özdemir, N. \& Yalçın, M. T. (2019). Ortaöğretim öğrencilerinin akademik başarısı ile okul ve öğrenci düzeyi değişkenler arasındaki ilişkilerin incelenmesi: İki düzeyli yol analizi. Ĕgitim ve Bilim, 44(200), 93-116.

Özdemir, Y. (2015). Ortaokul öğrencilerinde okul tükenmişliği: ödev, okula bağlllık ve akademik motivasyonun rolü. Adnan Menderes Üniversitesi Ĕ̆itim Fakültesi Eğitim Bilimleri Dergisi, 6(1), 27-35.

Pascarella, E. T. (1984). College environmental influences on students' educational aspirations. The Journal of Higher Education, 55(6), 751-771.

Plucker, J. A. (1996). Constract validity evidence for the student aspiration survey. Journal of Research in Rural Education, 12(3), 161-170.

Plucker, J. A. (1998) The Relationship between school climate conditions and student aspirations. The Journal of Educational Research, 91(4), 240-246.

Redd, Z., Brooks, J. \& McGarvey, A. M. (2001). Background for community level work educational adjustment in adolescence:Reviewing the literature on contributing factors. Washington, DC: Child Trends.

Roeser, R.W., Midgley, C. \& Urdan, T. (1996). Perceptions of the psychological environment and early adolescents’ psychological and behavioral functioning in school: The mediating role of goals and belonging. Journal of Educational Psychology, 88, 408-422.

Rothon, C., Arephin, M., Klineberg, E., Cattell, V. \& Stansfeld, S. (2011). Structural and sociopsychological inluences on adolescents' educational aspirations and subsequent academic achievement. Social Psychology of Education, 14(2), 209-231.

Sanders, J., Munford, R. \& Boden, J. M. (2017). Pathways to educational aspirations: resilience as a mediator of proximal resources and risks. Kötuitui: New Zealand Journal of Social Sciences Online, 12(2), 205-220. 
Sarı, M., Ötünç, E. \& Erceylan, H. (2007). Liselerde okul yaşam kalitesi: Adana ili örneği. Eğitim Yönetimi: Kuram ve Uygulama 50, 297-320.

Shankar, J., Ip, E. \& Khalema, N. E. (2017). Addressing academic aspirations, challenges, and barriers of indigenous and immigrant students in a postsecondary education setting. Journal of Ethnic \& Cultural Diversity in Social Work, DOI:10.1080/15313204.2017.1409675

Silins, H. \& Mulford, B. (2004) Schools as learning organizations: Effects on teacher leadership and student outcomes. School Effectiveness and School Improvement, 15, 443-466.

Skinner, E., Furrer, C., Marchand, G. \& Kindermann, T. (2008). Engagement and disaffection in the classroom: Part of a larger motivational dynamic? Journal of Educational Psychology, 100(4), 765-781.

Smith, M. L., Mann, M. J., Georgieva, Z., Curtis, R. \& Schimmel, C. J. (2016). What counts when it comes to school enjoyment and aspiration in the middle grades, RMLE Online, 39(8), 1-13.

Şimşek, Ö. F. (2007). Yapısal eşitlik modellemesine giriş: Temel ilkeler ve Lisrel uygulamaları. Ankara: Ekinoks Yayınları.

Şişman, M., Güleş, H. \& Dönmez, A. (2010). Demokratik bir okul kültürü için yeterlilikler çerçevesi. Uşak Üniversitesi Sosyal Bilimler Dergisi, 3(1), 167-182.

Terzi, A. R. (2014). Üniversite öğrencilerinin güç mesafesi ve belirsizlikten kaçınma algıları üzerine bir araştırma. Afyon Kocatepe Üniversitesi Sosyal Bilimler Dergisi, 6(2), 65-76.

Thornberg, R. \& Elvstrand, H. (2012). Children's experiences of democracy, participation, and trust in school. International Journal of Educational Research, 53, 44-54.

Veiga, F. H., Robu, V., Moura, H., Goulão, F. \& Galvão, D. (2014). Students’ engagement in school, academic aspirations, and sex. International Perspectives of Psychology and Education. Lisboa: Instituto de Educação da Universidade de Lisboa.

Wang, M. C., Haertel, G. D. \& Walberg, H. J. (1997). Fostering educational resilience in innercity schools. Erişim adresi: https://files.eric.ed.gov/fulltext/ED419856.pdf

Wang, M. \& Holcombe, R. (2010). Adolescents' perceptions of school environment, engagement, and academic achievement in Middle School. American Educational Research Journal, 47(3), 633-662.

Yağc1, E. (1998). Demokrasi ve Eğitim. Eğitim ve Bilim, 22(107), 15-22.

Yanık, M. (2018). The effects of on the high school students engagement level of sport events. Spormetre, 16(1), 73-78. 
Yavrutürk, A. R. (2019). Lise öğrencilerinde okul bă̆lılı̆̆ının yordayıcıları olarak sosyal destek ve okul iklimi. Yüksek lisans tezi. Tokat Gaziosmanpaşa Üniversitesi, Tokat.

Yavuz-Tabak, B. (2017). Okullarda demokratik okul kültürüne ilişkin görüşlerin belirlenmesi. Doktora tezi. Gazi Üniversitesi, Eğitim Bilimleri Enstitüsü, Ankara.

Yüksel, M. \& Hayırsever, F. (2019). Determination the views of high school students on theschool and their feelings about their schools. Ankara University Journal of Faculty of Educational Sciences, 52(2), 401-434.

\section{Summary}

\section{Introduction}

In Turkey, high school education represent a critical period when students prepare for university education and make their decision of future profession. Naturally, the academic aspirations of the students at this educational level have great importance in terms of getting into a university or their professional orientation. Not only in Turkey but also all over the world, academic success in high schools and their equivalent is seen as an important factor for university entrance. Indeed, research shows that university education is associated with outcomes such as good quality of life and economic gain. For this reason, it can be seen that having an adequate academic aspiration to be able to be successful at the university exam for high schools students are very important. The starting point of this research is the need to identify the premises that increase students' academic aspirations. In this context, democratic school culture and school engagement were thought to have an important role on academic aspiration.

Democratic school culture refers to a culture where all students (i) have equal rights in the school environment, (ii) can benefit fairly from school facilities, and (iii) have the right to participate and speak actively on certain topics. It is stated that only in such a school environment, it is possible for students to actively participate in school life, and thus so their engagement to school can improve. School engagement is defined as the students' attending the school voluntarily, behaving according to the school rules, and voluntary participation in all activities in the school and in the classroom. And it is thought that high level of school engagement may improve academic aspiration. In this context, students' academic aspiration is explained by their desire to rise in their school life, openness to be inspired by the school, achievement motivation, take pleasure in being at the school and tendency to act with determination because they believe that what they learn at school will be useful in the future. 
The purpose of this study is to determine the high school students' perceptions about democratic school culture, the level of their school engagement, and academic aspirations and to find out the relationship between these variables. For this purpose, it was investigated whether school engagement has a mediating effect in the relationship between democratic school culture and academic aspiration. Possible relationships between variables were hypothesized based on the literature and these hypotheses were tested. Hypotheses are; Hypothesis 1. Democratic school culture perception is a significant predictor of school engagement. Hypothesis 2. Democratic school culture perception is a significant predictor of academic aspiration. Hypothesis 3. School engagement is a significant predictor of academic aspiration. Hypothesis 4. School engagement has a mediating effect on the relationship between democratic school culture and academic aspiration.

\section{Method}

The research was designed as a relational screening model. The sample of the study was composed of 682 high school students studying in the central district of Usak. The data were collected from the students on a voluntary basis with both Democratic School Culture Scale, School Engagement Scale, and Academic Aspiration Scale. Before starting the analyses, the validity and reliability of the scales were analyzed. After then, prerequisite tests were also carried out. In order to test the hypotheses of the research, firstly, the means of variables, correlation coefficients and regression weights between the variables were calculated. In the calculation of whether there is a mediating effect of school engagement on the relationship between the democratic school culture perception and academic aspiration, firstly the measurement model was calculated and then the mediating test was carried out. To test the mediation effect again, the sobel test was also done.

\section{Findings}

According to the research findings, the democratic school culture perceptions, school engagement and academic aspiration of high school students are at a medium level. The scores of students' school engagement showed that the highest mean belongs to "behavioral commitment”, while the lowest mean belongs to "affective commitment”. When the dimensions of academic aspiration are analyzed, it can be seen that the highest average belongs to the dimension of "ambitions" and the lowest average belongs to the dimension of "school inspiration”. The correlation coefficients between variables showed that there was a moderate, positive and significant relationships between democratic school culture, school engagement and academic aspiration. In addition, it was found that there was a high level of positive, 
significant relationship between school engagement and academic aspiration. When looking at the regression coefficients between the variables, it was determined that the perception of democratic school culture is a significant predictor of school engagement and academic aspiration. In addition, school engagement is determined to be a significant predictor of academic aspiration. As a result of the calculated measurement model and mediation tests, it was determined that school engagement has a mediating effect on the relationship between high school students' perception of democratic school culture and their academic aspirations.

\section{Conclusion and Recommendations}

In the light of these results, it is recommended that school principals provide the necessary conditions for creating a democratic school culture and encourage teachers in democratic classroom management. However, a democratic school culture will be possible not only by explaining democratic living conditions, but also by applying it, by being a role model and by providing a democratic school life to the whole school community. In this respect, school principals and teachers need to determine the structural and process-oriented conditions for a democratic school and classroom life. It is very important to take into account students' interests, needs and wishes on this subject, implement the democratic values and maintain them. A democratic school culture will reach a realistic structure only when it is continuous and becomes a lifestyle.

This research was carried out with high school students and the role of democratic school culture and school engagement on increasing academic aspiration was emphasized in the study. In the future studies, to investigate the different premises that increase academic aspiration and to support and detail them with qualitative research will contribute to the field. In addition, other managerial factors that improve students' school engagement can be revealed through qualitative research. In this context, conducting the same studies not only with high school students but also with other educational levels can contribute to the field. 